\title{
THE CONCEPT OF MULTI-DOMAIN OPERATIONS AND ITS MULTINATIONAL UNDERSTANDING
}

\author{
Crăișor-Constantin IONIȚĂ, Ph.D., \\ Researcher, Centre for Defence and Security Strategic Studies, \\ „Carol I” National Defence University, Bucharest, Romania. \\ E-mail: ionita.constantin@unap.ro
}

\begin{abstract}
The international competition on emerging technologies rises a new and very dangerous threat for global and regional security because of the easy access to the procurament of very high-tech and sensitive defence material. The race for who will control some domains from the future operating environment is between the United States, Russia and China, but several other state and non-state actors have reconsidered their high-tech strategies, already. It is about India, Iran, Japan, Israel and the European Union as a whole, as well as transnational terrorist and organised crime organisations or multinational companies. At the same time, the last technological developments have created a huge discrepancy in the Revolution in Military Affairs (RMA), especially because of letting far behind doctrines and the organisation of military structures for combat. This anacronism is evolving with the intent of gradually replacing regular fighters and current formations in the modern battlefield with robots/androids and joint human-machines teams. As a result, it has become imperative to develop new concepts/strategies for future conflicts that brings together all elemnts of advanced technologies and coordinates their joint acions on any potential adversary, in order to achieve a total and quick victory. This material will analyse the US Army's concept of Multidimensional Operatios and how it is understood at the Allied level.
\end{abstract}

Keywords: emerging technologies; Artificial Intelligence; machine learning; humanoid robots/androids; Multi-Domain Operations.

\section{Introductory landmarks}

The complex and unforeseen events that took place worldwide in the last decade have changed the way of thinking and conducting military conflicts. As a result, the United States has considered that it is time for a new framework concept for the future military conflicts, a strategic approach of achieving complete victory in any type of warfare.

The many attempts and strategic experiments to develop new operational and strategic concepts are still undergoing at the levels of American military thinkers and defence researchers. At the end, only two selected concepts remained to be discussed and agreed at Pentagon - the US Army's concept of „Multi-Domanin Operations” and the US Government Agency for Advanced Defense Research Projects (DARPA)'s proposal of „Mosaic Warfare”. Both strategic approaches are meant to take over the innovations and modernisations that appeared in the Military Science and Art, made by the different military philosophies, starting with Sun Tzu. At the same time, the existance of the two strategic documents created a dillema in the new military thinking between military thorists and defence researchers. 
Indeed, many of the innovative ideas that characterise this new approach to the future warfare might be also found in Sun Tzu's "Art of War". But they were processed and adapted to the innovative tactics of the German's "Blitzkrieg”, waged against the Allies in World War II, when an asymmetric advantage was obtained by using an overwhelming force of armor, motorised infantry, artillery and aviation, to create temporary breaches in the opponents' static defense that, in turn, was successfully exploited later.

Other military conceptual elements were taken from the "Assault-Breaker" strategy, being established as a compensation for the Vietnam disaster. Starting from the tank-airplane binomial of German tactics, the second generation strategy developed a first strategic framework focused on the deployment of an initial system-of-systems capability, in which air sensors and missile systems worked together to overcome, as a military power, the huge Red Army counterpart, without reaching nuclear escalation.

A third generation of US military strategy included the concept of "Effect-Based Operations (EBO)", which emerged from lessons learned in Afghanistan and Iraq. But the EBO concept has been adapted more to Military Operations Other Than War (MOOTW), leaving the conventional war to combine, on an ad-hoc basis, high-tech platforms and existing superdeveloped capabilities, with parts from already elaborated concepts and doctrines (developed for the use of each existing weapons platform), to which was also added the poor training of troops for the efficient use of those platforms. What has been preserved from EBO is represented by "nodes" and "effects."

The complex and unforeseen events that took place worldwide after 2014 demonstrated the need to change the way of thinking and conducting military conflicts. Thus, since 2015, US military leaders have considered that it is time for a new strategy for future wars, a strategy of obtaining the full victory in any kind of conflict.

In my book, ,Multi-Domain Operations Versus the Mosaic Warfare. Future Conflicts's Dillema Between Multi-Domain Operations and the Mosaic Warfare”, published in 2021, I presented the numerous attempts proposed by American military theorists in the last ten years, starting from strategic concepts - „Army After the Next" (2010), ,C Capstone Concept for Joint Operations" (2012), „Army Operating Concept” (2014), ,AirLand Battle” (2015), or „,US Marine Corps Operating Concept” (2016) and ending with „Multi-Domain Battle” (2017). All these newly proposed concepts had in common the desire of military leaders to change the way of thinking and conducting future conflicts, after the operationalisation of Russian and Chinese Anti-Access/Aerial Denial systems (A2/AD), which prevents the US from intervening in regions controlled by Moscow and Beijing.

The main idea arising from the continuity of those operational concepts was the existence of a "man-machine" team to fight successfully in future wars. The idea was taken from the book "Average is Over" of the American writer Tyler Cowen, in which machines always beat the great masters of chess, but a joint action of the chess player with the machine against another machine has great chance of success. Another idea was to realise a real synergy between multi-domains of action, by ensuring the complementarity of defense capabilities and not increasing their number, leading to an increased efficiency of their use whilst covering existing vulnerabilities, which, in turn, leads to the achievement of integrated actions of joint forces as one.

In order to develop a new strategy for future wars, the US Army launched, few years ago, the "Multi-Domain Battle 2017" concept for changing the way of thinking and conducting future conflicts, with the aim of penetrating enemy's A2/AD systems and restoring the freedom 
STRATEGIES XXI International Scientific Conference

The Complex and Dynamic Nature of the Security Environment

of strategic action in regions controlled by Moscow and Beijing. One year later, in 2018, scientific researchers from DARPA proposed a new strategic approach, called ,the Mosaic Warfare", to bring together all battle platforms to establish a complete picture of a quick and decisive victory against any aggressor, as well as to develop an appropriate package of skills. Both initiatives presented new operational concepts that would allow all joint weapon systems to work together, thus massing the fire and not the forces, in order to solve the complexity of modern operating environment and transform it into an asymmetric advantage.

\section{The Development of the Concept}

Starting with 2016, Army military theorists were very much focusing on solving the challenges to achieve cross-domain synergy through assessing and solving the luck of desired expertise needed, training and education shotfalls, manning, and classification and compartmentalisation of capabilities. The final result was to consider "cross-domain synergy as a people problem" (McCoy 2017, 4), a real constrain of having the right people, training, equipment, and doctrine to win the 21st Century Warfare.

Also, in my book I described the concept of "Multi-Domanin Battle", which was launched one year later. This initial concept was designed to present the new perspective of how US military fights, both in purpose and design, to respond to the new challenges of incorporating technological advancements and diffusion, leveraging weaponised information and addressing potential adversaries' disruptive political aims designed to upend the current international order. It is already considered by US military commanders that potential adversaries have now the capability to prevent US forces from gaining access into the thater, fix them by limited US maneuver capabilities, and fracture their interdependent joint forces. (McCoy 2018, 1)

In the Concept Vision 1.0 "Muti-Domain Battle: Evolution of Combined Arms for the $21^{\text {st }}$ Century", the art of realising cross-domain synergy is related to the convergence and integration of systems. The convergence is defined as "the integration of capabilities across domains, environments, and functions in time and physical space to achieve a purpose" (McCoy 2018, 2), whilst the integration of systems is focusing not just on the people and processes, but the technological solutions required to achieve the respective synergy. (Ionita $2021,11)$

It is woth mentioning that current work in cross-domain synergy fails to aknowledge that existing systems and programmes of record are stove-piped and federated to the point that cross-domain maneuver and fires would require a human solution. So far, the lessons learned from Afghanistan and Iraq demonstrates that US military continues to fight as a large expeditionary force, massing forces in forward support areas in the theatre, with training and exercises designed to deter and prepare for the fights to come. Their lethality is unmacthed with deployed capabilities, becoming a weakness which is well-known and exploited by adversaries.

At the same time, the important notions of the Military Art - like space and time, deep, close and rear -, has evolved and today's modern operating environment became simultaneously expanding and compressing, increasing the complexity by which the war can be fought. The distance/space factor might reduce the limiting effect if we can engage lethal and non-lethal fires from anywhere around the globe. This is the case of increasing the number and importance of space and cyber-based capabilities, which can generate lethal and non-lethal 
fires anywhere around the globe. Their effects have almost near-instantaneous impacts without consideirng the geographic space and political boundaries.

As Mr. Work presented during his speech at the US Army War College on 8 April 2015, "the combination of guided munitions and informationalized warfare - being able to kill by signature alone -, is a critical variable for military success in twenty-first-century warfare. Informationalized warfare is the combination of cyber, electronic warfare, information operations, deception, and denial to disrupt our command and control and thereby give the enemy an advantage in the decision cycle. By combining informationalized warfare with the accuracy and relative low cost of guided munitions, the victors on the next battlefield will fix and fracture their adversary with quick, decisive, and lethal effects across the entirety of the battlespace and immediately consolidate gains to make any military response politically unpalatable." (McCoy 2017, 2)

Therfore, the "Multi-Domain Operations" concept, as it was renamed in the Concept Version 2.0, requires truly integrated, resilient, and rapidly deployable military capabilities designed to achieve cross-domain maneuver and fires, capable of working together in a convergence that goes beyond synchronisation. (McCoy 2017, 3) Within the new vision, the core capabilities required to create an advantage in order to win the future fight should respond to one or multiple critical tasks, like competition, convergence, resilience, and force posture.

\section{Mr. Senge's Model for Future Warfare}

Being a guiding vision, the new concept has the possibility to resolve both today's operational environment and tomorrow's vision. As previously mentioned, it is developed to fulfil three core tasks - competition and the conflict continuum, compression, convergence, and expansion of the operating environment, as well as the future Force Components -, which represents, in fact, the foundation of the future of warfare for the US military.

The idea of competition seems to be perceived today by the conflict continuum (JP 3-0 Joint Operations 2018, 31), which represents the span of possibilities between peace and war, requiring American forces to be proficient across the full range of military operations „In short, the concept looks at competition as a period outside of open conflict; it is a contest over national interests with an adversary that exists short of conflict. To compete (and prevail), you must directly link your capability of waging all-out war with what you do in competition. As the concept states, this is not a new idea. Others might observe that it's no different than what we do today. But while we saythat our activities - from shaping to dominating to enabling - are connected, in practice, they too often are not. We must evolve the models we use to plan and execute operations if we want to remain competitive in the twenty-first century." (McCoy 2018, 3).

Unfortunatelly, the mental models described by the American scientist Peter M. Senge in his book ${ }^{1}$, The Fifth Discipline: The Art \&amp; Practice of The Learning Organization” do not represent a strong point for the US Army, even if the conflict continuum and phasing constructs are idealistic mental models for commanders, planners and decision-makers. This is because mental models are not solutions in themselves, but they give planners a way of phasing the military major operations. (Senge 2006, 187-188) The US Army's continuum conflict mental model is defined by competition short of conflict, conflict itself, and the return to competition. Gen. David Perkins, a former commander of the US Army's Training and Doctrine

\footnotetext{
${ }^{1}$ N.A.: Mental models are defined as deeply ingrained assumptions, generalizations, or even pictures or images that influence how we understand the world and how we take action.
} 
STRATEGIES XXI International Scientific Conference

The Complex and Dynamic Nature of the Security Environment

Command, broadened the aperture of competition to a strategic perspective in a "Military Review" article as: "There is and always will be strategic competition. You are either winning or losing, present tense. Seldom will conflict result in a permanent win or loss. The linear depiction of peace to war and back again must be revised to reflect the cyclical nature of war where there are only positions of relative advantage." (Perkins, 2017). According to this mental model, there is not such thing as peace, but only competition and conflict. When settleing for peace, one might loose sight of how world is evolving and immediately place him/her at a disadvantage.

If mental models, like the conflict continuum and phasing construct, help define and organise problems and create possible solutions, the ones used in Afghanistan and Iraq to guide policy-makers, commanders and planners seems to be inadequate and misinterpreted by their costommers. This is why, the general perception is that the US Army needs revised models to give it the ability to stay competitive in a constantly changing environment.

In order to build up new mental models the US military thinkers should understand that the conflict continuum is not relational, but cyclic, in which military and non-military actions impact one another sequentially and simultaneously without a clear timeframe. These impacts change the environment and force competitors to control the operational tempo of the cycle, if they want to remain competitive. It also requires a change in how military operations will be modelled in the future.

A new mental model, focusing on the problem of competition confined by specifying time and space, provides an option outside of systematic build up of forces in shaping operations. In this new model, strategic plans should no longer be about steady-state shaping operation, but about winning in the competition period. Contingency plans should no longer be about setting the theater, but applying the ground work to effectively deter armed conflict, and if necessary, defeat adversaries if and when conflict arises. (Ionita 2021, 15)

Therefore, it is imperative necessary to build up a future menthal model to solve both the competition and conflict. Thir model should incorporate shaping considerations of future operating environment, as well as capability development to design new possible forces for dettering any possible adversary and providing resilience at home.

\section{Multi-Domain New Challenges and Oportunities}

After the North Atlantic Treaty Organisation (NATO) decided, in 2020, to include two new domains of operations in its Comprehensive Framework for Allied Operations - space and cyber -, more member states have started to think about and develop the US Army "MultiDomain Operations" concept. In order to bring the concept at the strategic level, British military thinkers have transformed it into the "Multi-Domain Integration (MDI)" one, considering that the new approach will change the way British Forces operate and war fight, and the way capability are developed. According to the UK "Integrated Operating Concept 2025 ", the UK Development, Concept and Doctrine Centre (DCDC) issued, in November 2020, the "Joint Concept Note 1/20 Multi-Domain Integration”, in which MDI is presented as ,the posturing of military capabilities in concert with other instruments of national power, allies and partners; configured to sense, understand and orchestrate effects at the optimal tempo, across the operational domains and levels of warfare." (Joint Concept Note 1/20 Multi-Domain Integration 2020, 3). 
The aim of implementing this concept is to better compete with potential adversaries in this era of persistent competition, by conducting wars in a way that generates advantage through being better integrated across the three levels of warfare and all five operational domains: maritime, land, air, space, and cyber. (Joint Concept Note 1/20 Multi-Domain Integration 2020, 12)

The Western military thinkers already consider that the potential adversaries use different types of actions to achieve their objectives bellow the so-called war - "political warfare", "hybrid war", "information superiority", "new-type war" or "multi-sphere operations (mnogosfernoy operatsii)" -, interoperating military and non-military capabilities with freedom acress to domains, both home and away, as well as using their gained experience in exploiting cyber, electromagnetic and information advanced technologies. Sophisticated operations that target systems are combined with more conventional military ones, like proxies, coercion, offensive cyber and lawfare, to disrupt Western systems in the early stages of any conflict and turn shaping operations into decisive ones.

The new threats pose by potential adversaries are exacerbated by technological advancement, precision effects, bluerred boundaries and time compression, which also represent drivers for change. This is why, the Western response is through multi-domain integration, because it seems that joint is no longer enough. As the JCN 1/20 stipulates, "MDI is about designing and configuring the Whole Force for dynamic and continuous integration of all global capabilities together, inside and outside the theatre, munitions and non-munitions, above and below the threshold of armed conflict. The greatest effect will be from drawing in as many capabilities as possible to apply combinations the adversary does not expect or cannot guard against. Forcing the enemy to defend all domains all the time from all directions will impose multiple dilemmas and open up vulnerabilities. It is not just an offensive concept; the ideas and designs are as applicable in defence and in engaging for influence." (Joint Concept Note 1/20 Multi-Domain Integration 2020, 11)

According to JCN 1/20, the multi-domain integration model comprises four tenets: (Joint Concept Note 1/20 Multi-Domain Integration 2020, 25):

- information advantage - enabling and effecting orchestration through comprehensive and persistent sensing and understanding of environments and audiences, which must be common across government and with allies;

- strategically postured - the global, domain-centric arrangement of capabilities;

- configured for the environments - readiness for multi-domain activity in operating areas and environments to influence the behaviour of selected audiences;

- creating and exploiting synergy - generating, timing and exploiting windows of opportunity for relative advantage by creating synergy.

In the current proposed model of MDI, there are a lot of challenges and opportunities. For example, the sense, understand, orchestrate functions are enabled and expressed just thorugh a Command, Control, Communications, Computers, Information, Surveillance and Target Acquisition (C4ISTAR) system, which is an agile command and control capability, augmented by autonomy and automation. Moreover, the respective system will require technical, procedural, cultural and educational leaps to become a force multiplier.

Strategic posturing means to deploy right military capabilties in right places and integrate them with non-militry ones and Allies/Partners, where the operational level will interate strategically controlled multi-domain capabilties (like space and offensive cyber) with tactical ones. In a dynamic MDI, Component Command structures might not be the ultimate solution. 
STRATEGIES XXI International Scientific Conference

The Complex and Dynamic Nature of the Security Environment

Tempo should be calibrated to be optimal in order to create windows of opportunities for exploiting the cross-domain synergy. There are identified or engineered within the combination of human, physical and information sub-environments according to relative domain strengths.

Still, the "Multi-Domain Operations" concept requires close reading and reflection to holistically address the complexity of future operating environment with considerable depth. For the respective concept to serve as a guiding vision for future conflicts it has to successfully incorporate technological advancements and diffusion, effectively leverage weaponised information, and efficiently address potential adversaries' disruptive political aims designed to upend the current international order.

Moreover, as the potential adversaries have already developed high-tech integrated systems, based on automation, machine learning, and Artificial Intelligence with the intent of using them in future conflicts, the "Muti-Domain Operations" concept has the main aim to go beyond present stove-piped and federated systems and programmes of record, in which crossdomain maneuver and fires require human solutions. It has to design new solutions for mannedunmanned teaming in the future.

The new concept of "Multi-Domain Operations" for future conflicts, being under development, represents the military innovative response to future treaths and challenges. It incorporates existing high-tech products and looks for perspectives and opportunities regarding how to achieve strategic advantages against potential adversaries in a future major conflict. Its main difference from other concepts, like "the Mosaic Warfare", is represented by the idea of who will be in lead inside the manned - unmanned teaming: the people or the machine.

The task organisation of forces and systems according to the specifics of the mission to be accomplished is not something new, as is the idea of using systems networks in conflict. What is truly new about this concept is the speed and complexity with which it can combine the package of available flexible forces with the reinforced Command-Control system with emerging technology, operations divided into action elements and Mission Command, in order to achieve a real framework of a future modern Maneuver Warfare, focused on information. The main goal is not to allow the opponent the necessary time to predict and understand what is going to happen. At the Pentagon, the aim is to create a new approach to SoS, which can be flexibly networked and quickly configured to ensure the ability to resilience of operators. That means the use of any system or unit that has those characteristic functions that allow them to combine with other elements to achieve a desired joint capability at the time and place as being chosen by commanders. As distinguished councelor Robert O. Work stated, "The Army that will find the most appropriate combination of technology and operational concepts will probably be at the top."

The implementation of the new technologies will decisively contribute to the MultiDomain Operations approach, being focused on obtaining a decisional advantage over an opponent. Support for decision-making by AI platforms, unmanned and autonomous systems, enhanced passive sensors, smaller weapons, and electronic and cyber warfare capabilities could impose complexity and confusion on an opponent and allow for targeted attacks on key targets. Thus, the emergence of a possible strategic paradigm on the preparation and conduct of future operations will be focused on the decision. 
So far, neither NATO nor Romania has moved to such an approach in the recently conducted Strategic Defense Review (SDR). Concerns about the use of advanced technologies and the development of Smart Military Bases are found in the scientific events of NATO and some developed Member States, at an early stage. Unfortunately, this will further deepen the technological gap between the US and the European side of the Alliance.

\section{BIBLIOGRAPHY:}

IONITA, Craisor-Constantin. 2021. Multi-Domain Operations Versus the Mosaic Warfare. Future Conflicts's Dillema Between Multi-Domain Operations and the Mosaic Warfare. Chisinau, LAP LAMBERT Academic Publishing.

Joint Concept Note 1/20: Multi-Domain Integration. 2020. London, UK Ministry of Defence, LCSLS Headquarters.

JP 3-0 Joint Operations. 2017. „Incorporating Change 1 on 22 October 2018.” Joint Chiefs of Staff, January 17, 2017. https://www.jcs.mil/Portals/36/Documents/ Doctrine/pubs/jp3_0ch1.pdf

MCCOY, Kelly. 2017. "The Road to Multi-Domain Battle: An Original Story”, Modern War Institute, October 27, 2017. https://mwi.usma.edu/road-multi-domain-battle-origin-story/

MCCOY, Kelly. 2018. "Competition, Conflict, and Mental Models of War: Whay you Need to Know About Multi-Domain Battle.” Modern War Institute, January 26, 2018. https://mwi.usma.edu/competition-conflict-mental-models-war-need-know-multidomain-battle/

PERKINS, David G., General. 2017. „Multi-Domain Battle the Advent of Twenty-First Century War." Military Review, noiembrie - decembrie 2017. https://www.army upress.army.mil/Journals/Military-Review/English-Edition-Archives/NovemberDecember-2017/Multi-Domain-Battle-The-Advent-of-Twenty-First-Century-War/.

SENGE, Peter M. 2006. The Fifth Discipline: The Art \& Practice of The Learning Organization, New York, Currency and Doubleday. 